eyepiece was used, would be only 25 in., or approximately equal in light-gathering power to a refractor of $20-i n$. aperture. A power not less than 216 would be necessary to give the full benefit of the large mirror. Although the eyepiece in question was not the only one employed, it may be important to take account of the fact that some of the observations at Parsonstown were not made with the full aperture of the telescope (Journ. B.A.A., vol. xxvi., p. 302).

\section{VENTILATION AND METABOLISM.}

$\mathrm{T}$

HE New York State Commission on Ventilation has issued an outline statement of the work done in I9I5. In the first report the Commission supported the view of the English physiologists, that the principal factors which make for comfort are temperature humidity and air movement, and that the effects of poor ventilation cannot be explained by the presence of volatile organic poisons in the air or any chemical change in the atmosphere. Even slight differences in temperature produce characteristic physiological responses in the body, affecting the output of physical work and likewise the inclination to do mental work. "In only one respect did the chemical quality of the air breathed show any characteristic effect on the body mechanism, this effect appearing in the slightly diminished appetite for food in a stale, unventilated atmosphere."

The Commission has now sought to find what quality of the stale used air has this effect. Is it the odour present? the increased $\mathrm{CO}_{2}$ ? or what? Artificial body odours and excess of $\mathrm{CO}_{2}$ have been introduced into a room ventilated with fresh air, but these have not produced the effect on the appetite. We do not believe that the Commission has ever properly eliminated the physical conditions. In their experiments they arranged that the temperature (wet and dry bulb) should be kept the same in the ventilated as in the stale-air chamber, and in the latter they placed a table fan to blow air upon the subjects, in order to imitate the current of air which circulated in the chamber ventilated with fresh air. There is no proof that the fan had this effect. It may not have ventilated the clothes of the subjects as effectually as the current of air did in the fresh-air chamber. We would suggest that the rate of cooling be measured with the katathermometer. Until this is done we cannot accept the view that the diminished appetite is due to any chemical alteration of the stale atmosphere. It seems more likely to be caused by a diminution in metabolism resulting from a lessened rate of cooling of the body surface.

The Commission says that for extreme mental concentration, involving an almost entire absence of physical exertion, a temperature of $75^{\circ}$ at $5^{\circ}$ per cent. relative humidity was preferable to $68^{\circ}$ at the same humidity, whereas for tasks involving greater motor effort, such as typewriting, the cooler temperature was coincident with the greater output. Here again data are wanted as to rate of cooling. Was the atmosphere a still one? In this country $63^{\circ} \mathrm{F}$. is regarded as a suitable temperature, but the comfort is far more a question of rate of cooling than of temperature. We would point out that mental concentration which demands an entire absence of physical exertion and so warm an atmosphere tells against the health of the body; the metabolism is greatly reduced, and with it the appetite; the digestive organs miss the massage due to bodily exercise and deep breathing; the circula tion is not made vigorous by the pumping action of the skeletal muscles and those of respiration; and the lungs are but little expanded by the shallow breathing. Daily open-air exercise is essential to compensate for NO. 244I, VOL. 97 ] such intense mental application if the health is to be maintained. Such work, together with high feeding, alcoholic pick-me-ups, and amusements taken in hot atmospheres, leads to the bodily flabbiness and middleage degeneration of the business man. The scholar requires his "constitutional" or else he will become hypochondriacal.

The Commission has examined the conditions of the nasal mucous membrane in hot and cold atmospheres, and generally confirms conclusions reached by the reviewer (cf. Lancet, May Io, I9I3). In the majority of subjects examined the reaction from heat is one of increased swelling, moisture, and redness, and the reverse from cold. Air blown upon the face by fans greatly modifies the effect. On going from the cold to the hot room with fans there is a decrease in the size of the inferior turbinates and in the amount of moisture. The characteristic change on passing from the hot to the cold condition with fans is an increase in the turbinates and secretion. The Commission reports that laundry workers show a high percentage of cases of atrophic rhinitis, the result of working in hot humid atmospheres. The changes of the nasal membrane produced by environment must materially affect the incidence of infection by "colds." This subject is dealt with by the reviewer in an article published in the British Medical Journal for April I5, I916.

Mr. Palmer, the chief of the investigating staff of the Commission, has fashioned a new sampling apparatus for the determination of aerial dust. Air is drawn, by means of an electric-driven fan, through a $\mathbf{U}$-tube containing some water. The water is thrown into a spray formation in a conical glass vessel attached to the $\boldsymbol{U}$-tube, and the air is washed of its suspended dust as it passes through the water shower. One hundred cubic feet of air can be put through in thirty minutes. The water can be evaporated and the dust weighed, or the dust can be estimated by the turbidity of the water against a set of standards, or the particles of dust-in a measured quantity of the water-counted under the microscope. The pernicious effect of dust on the lung is not properly realised by the public. Dust containing free silica is the most potent cause of phthisis prevalent in miners, granite and flint workers, etc. The motor-cars stir up clouds of dust from roads metalled with flint and granite. People dislike the dust on their clothes, but do not realise the damage it causes to their lungs. All dusts diminish the efficiency of the lungs and lead to lessened expansion and shortened breath-the asthma of dusty occupations. LEONARD Hill.

\section{THE AMERICAN PHILOSOPHICAL SOCIETY.}

THE annual meeting of the American Philosophical Society was held on April $1_{3}-\mathrm{I}_{5}$, during which nearly fifty papers were presented on a large variety of topics. The address of welcome was delivered by Dr. W. W. Keen, the president, who, with the vicepresidents, Dr. W. B. Scott and Prof. E. C. Pickering, presided at the various meetings.

We are able, from the material which the secretary, Prof. A. W. Goodspeed, has sent us from Philadelphia, to give brief abstracts of some of the papers which were read.

Dr. R. F. Bacon, "The Work of the Mellon Institute in its Relations to the Industries and to the Universities ":-

The first industrial fellowship at the Mellon Institute was founded through a grant from a baking company which desired to improve its product. The sum of money given was used, as has been all 
the money which has been subscribed to industrial fellowships, with the exception of small sums for the purchase of very special apparatus, to secure the services of a man who had shown a gift for research to devote all his time to certain problems connected with the baking industry. During the five years which have elapsed since the establishment of the first fellowship forty-seven distinct business organisations have endowed one hundred and five one-year fellowships. The total amount of money contributed to the institute for the five years ending March $\mathbf{I}$, 1916, was $72,000 l$. In addition to this sum $4260 l$. was awarded in bonuses to fellows for the successful completion of problems. During the five years the institute itself expended about $35,000 l$. Besides this amount, the building and permanent equipment of the institute represent an investment of between $60,000 l$. and $70,000 l$. That the results obtained under the industrial fellowship system of the Mellon Institute have justified the expenditure of these sums of money has been shown by the fact that during the first four years seven out of each ten problems assigned to the institute for study were solved to the satisfaction of the donors. A large percentage of the fellowships were renewed, showing the confidence which industrialists have in the institute. Twenty-five patents have been granted to the holders of fellowships, and there are as many more pending. Above all, some twenty new processes developed in the institute are now in actual operation on commercial scales.

Dr. G. F. Atkinson, "The $\mathrm{F}_{2}$ Generations, and Back- and Inter-crosses of the $\mathrm{F}_{1}$ Hybrids between Enothera nutans and pycnocarpa":-

The result of the observations shows that in the $F_{1}$ generation from a cross between two feral, non-mutating species quadruplet hybrids appear in the $\mathrm{F}_{1}$ generation; one is a blend and self-sterile, but its pollen and egg cells are fertile; two of the degregates are fixed types and breed true, while the fourth hybrid (third segregate) appears to split in the second generation. The back-and inter-crosses show either striking examples of patrocliny, or splitting into two types in some cases, into three types in other cases. But no new types (with a single exception) appear; they all conform to one or other of the six types, the primary parental types, or one or more of the $F_{1}$ hybrid types. The single exception is a mutant of the dwarf gracilis type.

Prof. J. M. Coulter, "Inheritance through Spores":-

The current work in plant genetics suggests the question of the most favourable material. If sexual forms are desirable, it seems obvious that the most primitive should be included in experimental material, since in such forms the sex act is not involved with other structures, the origin of the sexual cells is observable, and the whole situation lends itself to more complete control and analysis. The sexual cells, however, are genetically related to spores, so that the origin of spores and their behaviour in reproduction are preliminary to the origin of gametes and sexual reproduction. Reproduction by spores, therefore, is a field rich in experimental possibilities. Analysis of the conditions of spore formation furnishes a clue to the additional conditions necessary for gamete formation; experimental modification of the "germ plasm" is more simple and definite than in complex material; and breeding from spores with essentially pure lines is especially favourable for securing more definite data in reference to the possibilities of variation and inheritance.

Prof. W. J. V. Osterhout, "The Dynamics of Antagonism ":-

If two toxic substances af itagonise each other this is called action antagonism. An accurate measure of NO. 244 I, VOL. 97$]$ antagonism is afforded by determining the electrical resistance of living tissues. Toxic substances cause a fall of resistance, but if in a mixture of two such substances resistance falls less rapidly, it is evident that this is due to antagonism. In the case of the common kelp, Laminaria, $\mathrm{NaCl}$ causes a fall of resistance, while $\mathrm{CaCl}_{2}$ causes a rise, followed by a fall, of resistance. In mixtures of $\mathrm{NaCl}$ and $\mathrm{CaCl}_{2}$ the resistance rises and then falls; by using the right proportions the fall may be made very gradual. These facts may be explained by assuming that the resistance is due to a substance the production of which is accelerated by $\mathrm{CaCl}_{2}$, while its decomposition is checked by a compound formed by the union of both $\mathrm{NaCl}$ and $\mathrm{CaCl}_{2}$ with a substance in the protoplasm. This throws new light on the manner in which salts act in preserving life. It has been found that the electrical resistance rs a very delicate and accurate indicator of the vitality of protoplasm, since any kind of injury is at once indicated by a fall of resistance. This permits a quantitative meaning to be given to such terms as vitality, injury, recovery, and death. The mechanism by which changes in resistance are produced by salts is therefore of great importance. The facts here presented give a new insight into this mechanism.

Prof. F. Ehrenfeld, "Jointing as a Fundamental Factor in the Degradation of the Lithosphere" :-

In most text-books the question of land surface levelling or degradation is considered more from the view-point of the atmospheric or other surface cause than from that of the construction of the solid portions of the earth itself. This is a somewhat mistaken view to take of the case, as the stony mass of the earth has been shown by many geologists to be subject to a constant fracturing, or jointing, which shows itself in various ways, such as influence on river drainage, repeated groups of islands, bays along sea coasts, and in certain types of volcanic and earthquake appearances. The paper discussed these and also the subject of marine planation to produce a lowering of the land below sea-level. Illustrations of such marine action were shown from the Maine coast and also from the forms and positions of some of the Atlantic Ocean islands. This subject of the action of the sea to produce a general levelling, though much discussed some decades ago, has been neglected by many modern students, but is now becoming prominent under newer ideas, and this paper is in part a study of jointing in the mass of the lands to assist in such action and hasten continental land levelling and destruction by creating in the rock mass through joints great lines of weakness which, under the attack of both the atmosphere and the sea, compel the falling apart of the land. The author proposed a "law of joints " in which the controlling influence of joint lines was more definitely stated.

Prof. W. M. Davis, "Sinking Islands versus a Rising Ocean in the Coral-Reef Problem ":-

Since Darwin's voyage in the Beagle, eighty years ago, nearly all geologists who adopted his theory of coral reefs accepted also his postulate that the reefbearing islands have subsided with the subsiding ocean bottom. In later years, and largely under the leadership of Suess and Penck, the possible variation of ocean level around fixed islands has been emphasised. When it is seen that a rise of the ocean surface around still-standing islands would produce all the conditions that arise from Darwin's postulate of subsiding islands in an ocean of constant level, search should be made for some means of evaluating these two alternatives. The result of such a search shows that the theory of a changing ocean involves many extravagant complications which have not been sufficiently considered by those who accepted it; while the theory of subsiding islands is relatively simple and economical. Darwin's 
original theory is to be preferred on those grounds.

Prof. J. P. Iddings, "The Petrology of some South Sea Islands and its Significance" :-

The islands of Tahiti, Moorea, Huaheine, Raiatea, Tahaa, Bora Bora, of the Society group, and Hiva-oa and Nukahiva, of the Marquesas, were visited in order to ascertain whether the volcanic rocks composing them are of such a character that they support the theory of isostacy, which demands that the deep portions of the earth's crust, or the lithosphere, under the Pacific Ocean should consist of heavier material than that underlying the continent of North America. It was found that the volcanic rocks of these islands are noticeably heavier on the average than the igneous rocks occurring in various parts of the American continent. Each of the islands visited was found to be an extinct basaltic volcano, considerably eroded, and partly submerged beneath the sea.

Prof. J. J. Stevenson, "Coal Formation" :-

The doctrine that the fossil fuels from peat to anthracite are a continuous series has been the subject of renewed discussion within recent years. The author felt compelled to make serious investigation to free himself from doubts aroused by the statements of some authors. The general study has advanced so far as to justify presentation of the first part of his monograph. The plan adopted is to discuss the fuels in order of age, beginning with peat and closing with the Palæozoic coals. The first part considers peat and the Tertiary coals; the second will consider the Mesozoic and the Palæozoic coals. The author hopes to make evident the inherent probability of the doctrine that, in spite of difference in plant materials, the coals throughout form a connected series, not merely in mode of accumulation, but also in physical structure and in chemical composition.

Mr. G. Scatchard and Prof. M. T. Bogert, "A New and very Sensitive Indicator for Acidimetry and Alkalimetry and for Determining Hydrogen Ion Concentrations between the limits of 6 and 8 on the Sorensen Scale" :-

The authors have discovered that dinitrobenzoylene urea is an unusually sensitive indicator, and one which can be prepared easily, in any desired amount, from anthranilic acid. It changes from colourless to greenish-yellow with a change in hydrogen ion concentration from $1 \mathrm{O}^{-6}$ to $\mathrm{IO}^{-3}$, the development of the colour following regularly the decreasing concentration of hydrogen ion. It is very little affected by neutral salts or proteins, and not at all by the ordinary biological preservatives, chloroform and toluene. The colour does not fade perceptibly in two days, and does so but very slightly in a week. It therefore promises to be very useful in the measurement of hudrogen ion concentration of biological or other liquids in this important range, for which the previously known indicators are not very satisfactory.

Dr. F. W. Clarke, "The Inorganic Constituents of Marine Invertebrates":-

It is a commonplace of geology that many limestones are formed from the remains of marine animals, such as corals, molluscs, crinoids, etc. Some of these limestones are magnesian, some are phosphatic, and others are of the ordinary type, consisting chiefly of calcium carbonate. They were originally deposited at the bottom of the sea, and their composition depends upon the composition of the organisms which formed them. The present investigation has for its purpose to determine what each group of organisms contributes to the sediments; and in order to answer this question nearly 250 analyses have been made of the shells or skeletons of marine invertebrates, covering a range from the Foraminifera up to the Crustacea, and including also the coralline NO. 244I, VOL. 97$]$ algæ. It was already well known that corals and molluscan shells were composed almost entirely of calcium carbonate, and that fact has been verified. The shells of one group of brachiopods, however, consist largely of calcium phosphate, and that substance is also abundant in the Crustacea. These animals, and also vertebrate skeletons, contribute phosphates to the sediments. The Foraminifera, Alcyonaria, seafans, echinoderms, and calcareous algæ, with some minor groups or organisms, contain much magnesia, and therefore aid in the formation of magnesian limestones. Curiously enough, the amount of magnesium carbonate in any series of organisms varies with the temperature of the water in which the creatures lived, being small in cold and large in warm waters. A sea-urchin from Greenland, for example, contained 6 per cent. of magnesium carbonate, and one from near the equator contained more than I3 per cent. In certain algæ from the West Indies 25 per cent. was found. Furthermore, some organisms have their calcium carbonate in the form of aragonite, and others consist of calcite. The aragonitic organisms are all non-magnesian, while the magnesian forms are all calcitic. The data obtained in this investigation have been applied to the study of coral reefs, which owe their composition to all the creatures living upon them, and not to the corals alone. In fact, the corals are often of less importance than their associates.

Dr. W. Duane, "Some Relations between Matter and Radiation ":-

It is known that the impacts of atoms of electricity against atoms of ordinary matter produce radiation. Mr. Hunt, Dr. Webster, and the author have been investigating the relations between the energy of the atom of electricity and the frequency of the radiation it produces. The most striking facts discovered are that in the case of the so-called general radiation the energy required is strictly proportional to that frequency, and in the case of the so-called characteristic radiation the energy required is larger than in the preceding case and not always proportional to the frequency. High-frequency vibrations are associated with the central parts of an atom of matter, in which the electromagnetic field is very strong. In order to reach a point in an atom of matter where a given frequency of vibration is produced the atom of electricity must have at least enough energy to overcome a certain force of repulsion acting between them. If we follow out the line of reasoning and apply Maxwell's distribution law and what has been called the fourth power law to the case of the atoms of electricity flying about in a hot body owing to its thermal agitation, we arrive at an equation for the distribution of energy in the spectrum that represents the facts with considerable precision. These laws discovered by experimental investigation have a practical bearing on X-ray phenomena also. They indicate what must be done in order to produce those very high-frequency radiations that hitherto have been obtained from radioactive substances only.

Dr. L. A. Bauer, "Relation between Changes in Solar Activity and the Earth's Magnetic Activity, I902-I4" :-

No criterion of solar activity has been found to synchronise precisely with any quantity used as an index of the earth's magnetic activity. Thus, for example, the maximum magnetic activity in 1802 preceded the maximum sun-spot activity of that period by a vear. So again the recent minimum magnetic activity of the earth seems to have occurred in I9I2, whereas the minimum sun-spot activity did not take place until I9I3. or a year later. Then the amount of magnetic activity is not necessarily commensurate with that of solar activity, whatever measure of the latter be used. When the comparisons between the solar data 
and the magnetic data are made for intervals of less than a year-a month, for example-the lack of exact synchronism and the lack of proportionality between the two sets of changes become especially noticeable. Fortunately, beginning with 1905 , we have a new set of figures, the values of the solar constant, determined with high precision at Mount Wilson, California, by Dr. Abbot. Remarkable fluctuations are shown in these values, amounting at times to 1o per cent. of the value. The present paper makes a comparison between the annual changes in the values of the solar constant for the period I9O5 to 1914 , with the irregularities in the annual changes of the earth's magnetic constant. It is found that the two sets of data, in general, show similar fluctuations. Also, a closer correspondence is found between these two sets of changes than between either set and that of sun-spot frequencies. In brief, the solar-constant values furnish another index of changes in solar activity which may be usefully studied in connection with minor fluctuations in the earth's magnetism.

Dr. W. Patten, "Co-operation as a Factor in Evolution":-

The purpose of this discussion is to show that cooperation, or the summation of power, is the creative and preservative agent in evolution, and that the summation of power depends on co-operation in the conveyance of power. Co-operation in the inner life of the individual is a pre-requisite to co-operation in its external life. The larger physical volume and organic power of the individual are the means by which it finds the larger sources of supplies and the better ways of cosmic and social co-operation. What we call "evil" is that which prevents, or destroys, co-operation. "Good" is that which perpetuates and improves co-operation. The "struggle for existence" is a struggle to find better ways of co-operation, and the "fittest" is the one that co-operates best. The same laws which prevail in the inner and outer life of animals and plants prevail in the social life of man. Man's social progress is measured by the degree to which he has extended the mutually profitable giveand-take of co-operative action beyond himself to the family, tribe, and State, and into the world of life at large. The chief agents of civilisation-language, commerce, science, literature, art, and religion-are the larger and more enduring instruments of conveyance, which better enable the part and the whole to avoid that which is "evil" and to find that which is "good," and which yields a larger surplus for" "freecom."

Prof. G. H. Parker, "Types of Neuromuscular Mechanism in Sea-Anemones":-

In the origin of nerve and muscle the sea-anemone has been supposed to represent a step in which a nervous net of very primitive structure could throw into prolonged contraction the general musculature of the animal's body. An examination of the body of the sea-anemone shows that its muscular activities are of a much more diverse kind. They include, first, muscles that act under direct stimulation and without the intervention of nerves; secondly, muscles that are stimulated directly, as well as bv nerves; thirdly, muscles that are stimulated only by nerves and exhibit in these circumstances profound tonic contractions; and, finally, muscles that react in the same reflex way that those in the higher animals do. This diversity of muscular response has not been fully appreciated by previous workers.

Prof. E. C. Pickering. "Determination of Stellar Magnitudes by Photography":--

An immense amount of work is being carried on by observatories all over the world in determining the photographic magnitudes of the stars. It is of the utmost importance that all these magnitudes should be reduced to the same scale. Accordingly, in April, 1909, an International Committee was appointed, with members from England, France, Germany, Holland, Russia, and the United States. This committee met in 1910 and 1913 , and, after a most amicable discussion, agreed on a system in which all stars were to be referred to a standard sequence of stars near the North Pole. The magnitudes of the latter were determined at Harvard by Miss H. S. Leavitt by six different methods, using eleven different telescopes, having apertures from one-half to sixty inches. All gave accordant results, and were adopted by the committee. A simple method was found for transferring these magnitudes to stars in other parts of the sky, but here extraordinary sources of systematic errors presented themselves. For example, if two equal exposures were made on a plate, the second was found to give fainter images; if, by means of a small prism, exposures were made simultaneously with different apertures, the smaller aperture indicated a brighter magnitude than the larger when the stars were bright, and a fainter magnitude when they were faint. The colour equation was found to vary by different amounts, not only for different instruments, but for different magnitudes.

Miss A. J. Cannon, "A New Catalogue of Variable Stars ":-

So great has been the increase in the number of variable stars that a new catalogue now being compiled contains 464I stars, of which 3397 , or nearly threequarters of the whole, have been found at Harvard, and I244 elsewhere, by astronomers in nearly all portions of the civilised world. The variable stars are divided into five classes, dependent upon the character of their variation in light. The periods vary from three hours to 698 days. Determination of the periods and light curves of these stars constitutes a large piece of work. Much has been done at Harvard in this field, and many observations have been furnished by other astronomers for such determinations. No more suitable place could be found for the preparation of this catalogue than the Harvard Observatory, for the rich library of a quarter of a million stellar photographs furnishes the only complete material in the world for the studv of these stars during the last twenty-five years. By examining the past history of a star on these photographs, the investigator may far more readily find an answer to such perplexing questions as to whether a star is variable or constant, what is the length of the period, is the period changeable, what is the colour or the spectrum of the star. than by waiting months or years to accumulate additional observations.

During the morning of April $\mathrm{I}_{5}$ the following foreign members were elected:-Dr. F. D. Adams, F.R.S., of Montreal; Dr. W. L. Johannsen, of Copenhagen; and Dr. J. D. van der Waals, of Amsterdam.

\section{UNIVERSITY AND EDUCATIONAL INTELLIGENCE.}

THE sum of $3000 l$. has been bequeathed to the Yale University School of Medicine by Mr. Norman B. Bayley.

Prof. J. I. VAN Loghem has been appointed to the newly founded chair of tropical hygiene in the University of Amsterdam.

Dr. R. Armstrong-Jones has resigned, as from September next, after twenty-three years' service, the medical superintendency of Claybury Asylum. 